\title{
THE MANAGEMENT OF ACUTE RENAL FAILURE
}

\author{
Walter ElliotT, M.B., B.S., Molly Hill, M.B., Ch.B., M.R.C.P., D.R.C.O.G., \\ David N. S. KerR, M.Sc., M.R.C.P., M.R.C.P.(Edin.), and Rosalind AshCroft, Ph.D. \\ Department of Medicine, Royal Victoria Infirmary, Newcastle upon Tyme
}

The medical management of patients with acute renal failure was placed on a rational basis by Borst ${ }^{4}$ and Bull and his colleagues. ${ }^{7,8}$ They laid down three principles: (I) restriction of fluid intake to equal output; (2) elimination of dietary protein and provision of adequate calories to reduce endogenous protein breakdown and (3) the giving of no electrolytes except to replace known losses. Bull achieved these objects by feeding a synthetic 'diet' of glucose, peanut oil and water, known in Britain as the 'Bull regime'. The introduction of the artificial kidney ${ }^{12}$ has made the treatment of anuria more successful but even in artificial kidney units, the Bull regime remains the basis of treatment with only slight modifications.

We report here an attempt to apply these accepted principles to the treatment of anuria without the use of a synthetic diet in an artificial kidney unit equipped with an Alwall kidney. Sixty-four patients were referred to the unit in 1959 and 27 were treated with our modified regime.

\section{Water Balance}

Although the days of 'pushing fluids' and giving sodium sulphate infusions as treatment for anuria have almost passed, many patients arriving at an artificial kidney unit are overhydrated. This is mainly due to the delay in distinguishing acute renal failure from water and salt depletion, particularly in post-operative patients. Calculating fluid intake so that it does not exceed insensible loss plus urine output, is probably the most important part of the 'Bull regime'. An individual calculation is made for each patient to allow for variations in body build, pyrexia and extra-renal losses, but the average permissible intake during complete anuria is $500 \mathrm{ml}$. per 24 hours. On this small intake patients nearly always feel thirsty to a degree that is sometimes almost unbearable, and the presence of obvious overhydration does not seem to eliminate this thirst. It is, therefore, an obvious advantage to employ an artificial kidney that can extract water from the patient, to correct overhydration and then permit a slight increase in intake between haemodialyses.

The Alwall kidney is designed to do this in two ways. One method is to increase the osmotic pressure of the dialysing fluid by adding more dextrose. It has been shown in the experimental animal'1 that this method extracts water from both extracellular and intracellular fluid, and it appears to carry no serious risks even when the animal is in normal hydration. We use this method routinely, the dialysing fluid being made up to contain $140 \mathrm{mEq}$. $\mathrm{Na}, 113 \mathrm{mEq}$. $\mathrm{Cl}, 27 \mathrm{mEq}$. $\mathrm{HCO}_{3}, 5 \mathrm{mEq}$. Ca, $3 \mathrm{mEq}$. $\mathrm{K}, \mathrm{I} \mathrm{mEq} . \mathrm{Mg}$ and ro g. glucose per litre. The extraction of fluide is measured by accurate weighing on a bed weighing machine. There is considerable variato tion, but the average patient loses $1,500 \mathrm{ml}$. of $\rightleftharpoons$ fluid during a six-hour haemodialysis.

Water may also be extracted by raising the hydrostatic pressure of the blood within the Visking tubing. This method carries greater theoretical risks since fluid is apparently extracted from the extracellular fluid compartment only, ${ }^{21}$ and shock could result if excessive dehydration were allowed. It is also liable to burst the tubing. We employ it only in oedematous patients for an hour or so at the end of a dialysis.

The use of a high dextrose content in the dialysing fluid is equivalent to an infusion of about $100 \mathrm{~g}$. of dextrose given over six to eight hours. This is not excessive compared to the quantities often given to anuric patients by caval or intragastric drip ${ }^{7,10}$ and although the blood sugar may rise to $200-300 \mathrm{mg} / 100 \mathrm{ml}$. during the dialysis it returns to normal within a few hours.

\section{Control of Azotaemia}

It has long been thought that urea itself is harmless but this view has been seriously challenged, ${ }^{11}$ and it is almost certain that other protein breakdown products are also partly responsible for the 'uraemic state'. Complications, particularly haemorrhage and sepsis, increase if the blood urea is allowed to rise above $400 \mathrm{mg}$. $/ 100$ 


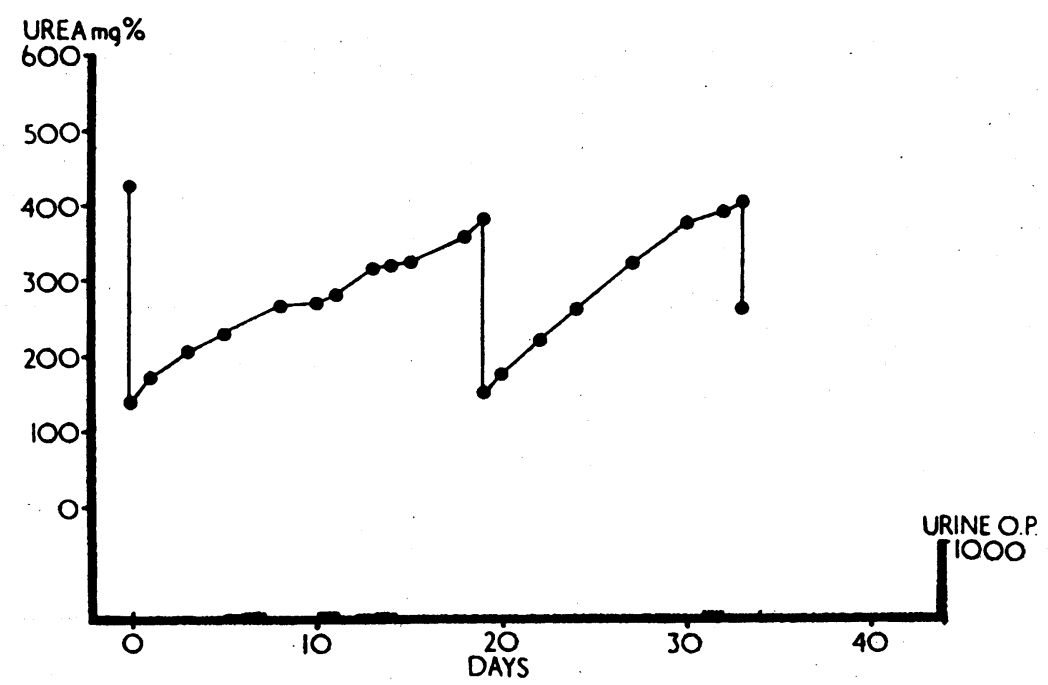

FIG. 1.-Graph showing the blood urea in a patient with complete anuria due to chronic nephritis. Haemodialysis was carried out on the Ist, 2oth and $34^{\text {th }}$ days.

$\mathrm{ml}$., and there is some evidence that survival is more probable if it is kept much lower than this. ${ }^{2,22,23}$ Although it is certain that the provision of non-protein calories reduces endogenous protein breakdown' ${ }^{9}$ the minimum amount required in uraemic patients is unknown. Bull's original diet contained $100 \mathrm{~g}$. of glucose and $400 \mathrm{~g}$. of peanut oil. This mixture was nauseating and had to be fed by Ryle's tube. Even then it caused vomiting (which was compensated by re-feeding the vomit) and diarrhoea, which was more difficult to correct. In most centres fat has now been omitted from the regime and the whole of the day's ration of food is given as $40 \%$ dextrose or lactose which, when fluid is restricted to $500 \mathrm{ml}$., provides only 800 calories a day. When this mixture is given by mouth throughout periods of oliguria lasting up to six weeks, it has a profound effect on the patient's morale. It also increases thirst, adds to the problems of mouth hygiene and encourages the development of parotitis and thrush. Because of the reluctance of many patients to take their nourishment in this form the practice of administering $40 \%$ dextrose intravenously by caval drip has acquired some popularity. ${ }^{5,24}$ This procedure is understandably unpopular in artificial kidney units as it uses up valuable veins which should be preserved for dialyses, and our experience with it in a number of other conditions confirms the impression of others, 18,25 that infection and embolism are relatively common and serious complications. Drips also interfere with the manipulation, frequent turning and early mobilization of patients. The 'carbohydrate-only' diets have un- doubtedly achieved considerable success ${ }^{15}$ and are in use in almost all artificial kidney units at present. Any reversion to free diet is therefore a serious step. However, in view of the complications, the very serious effect on the patient's morale and the inadequate calories provided by the glucose diet we have provided for our anuric patients a solid diet of not more than $22 \mathrm{mEq}$. $\mathrm{Na}$; $20 \mathrm{~g}$. of protein and $350 \mathrm{ml}$. of fluid per day. Highpotassium foods are not given but neither is potassium rigidly restricted. The remainder of the day's fluid ration is given as drinks and to swallow with medications. This diet can be made quite palatable and served attractively; allowing for rejections it provides about 1,500 calories per day. It has not been compared with the standard regime in a controlled trial, but experience to date suggests that it does not cause any significantly greater azotaemia. Fig. I shows the daily serum urea levels in an elderly lady with complete anuria. Forty per cent. dextrose was given on admission, but this proved so distasteful to her that after four days she was changed to the low protein diet. The average rate of rise of blood urea remained at $17 \mathrm{mg}$. $/ 100 \mathrm{ml}$. per day. It would appear that any increase in rate of urea formation due to the use of the more normal diet is insignificant. In many post-traumatic cases the rate of rise of blood urea is so high that small changes due to diet are of no importance and in these patients the higher caloric content of a solid diet has obvious advantages.

Vomiting has not been a serious problem in patients receiving this diet. Of 27 who have been treated on this regime, 17 never vomited at all and 
in only two was vomiting sufficient to necessitate some form of intravenous feeding. In the remaining eight patients a little vomiting occurred generally when the blood urea was high, immediately prior to dialysis.

McCracken and Parsons ${ }^{16,17,} 20$ have demonstrated that norethandralone is useful in reducing the rate of increase of blood urea at least in cases of renal failure complicating pregnancy; its effectiveness in patients with a high rate of catabolism is more difficult to assess and has not been established. Nevertheless, we administer it, or similar anabolic steroids, to all types of patient with acute renal failure.

\section{Electrolyte Balance}

By excluding electrolytes from the diet, Bull was able to minimize changes during the oliguric phase. Nevertheless in many cases dietary restriction alome cannot prevent rapid and fatal electrolyte imbalance ${ }^{19,13}$

The most serious initial problem is hyperkalaemia. Of our 64 patients, one died on admission of potassium intoxication and six others had the electrocardiographic changes associated with a high serum potassium. In at least one case the administration of potassium citrate to alkalinize the urine was partly responsible, and in others the risk could have been reduced by giving glucose, insulin, and an ion-exchange resin before transferring the patient. The conservative measures for dealing with potassium intoxication are reasonably effective. Fig. 2 shows the E.C.G. of a man admitted with a serum potassium of 8.5 $\mathrm{mEq} / \mathrm{l}$. The second tracing shows the improvement ${ }_{5}$ minutes later after the administration of ro g. of glucose and to units of insulin intravenously and Resonium A $15 \mathrm{~g}$. orally and $15 \mathrm{~g}$. rectally. The bottom tracing shows the restoration of the E.C.G. to normal after the serum potassium had been lowered to $3.0 \mathrm{mEq} / \mathrm{l}$. by haemodialysis.

Once the serum potassium has been corrected by dialysis it does not usually become a problem again. A maintenance dose of Resonium $A$ has occasionally been necessary, but it should be avoided where possible, since it is unpleasant to take and increases the intake of sodium, while taking up potassium in exchange. It also has a tendency to block the large bowel. Recurrence of serious hyperkalaemia after haemodialysis is uncommon. In all our patients in whom two or more dialyses were necessary, the later dialyses were required for azotaemia before the serum potassium rose to dangerous levels.

Acidosis is common in acute renal failure and, in the absence of serious chest lesions, the serum bicarbonate correlates reasonably well with the

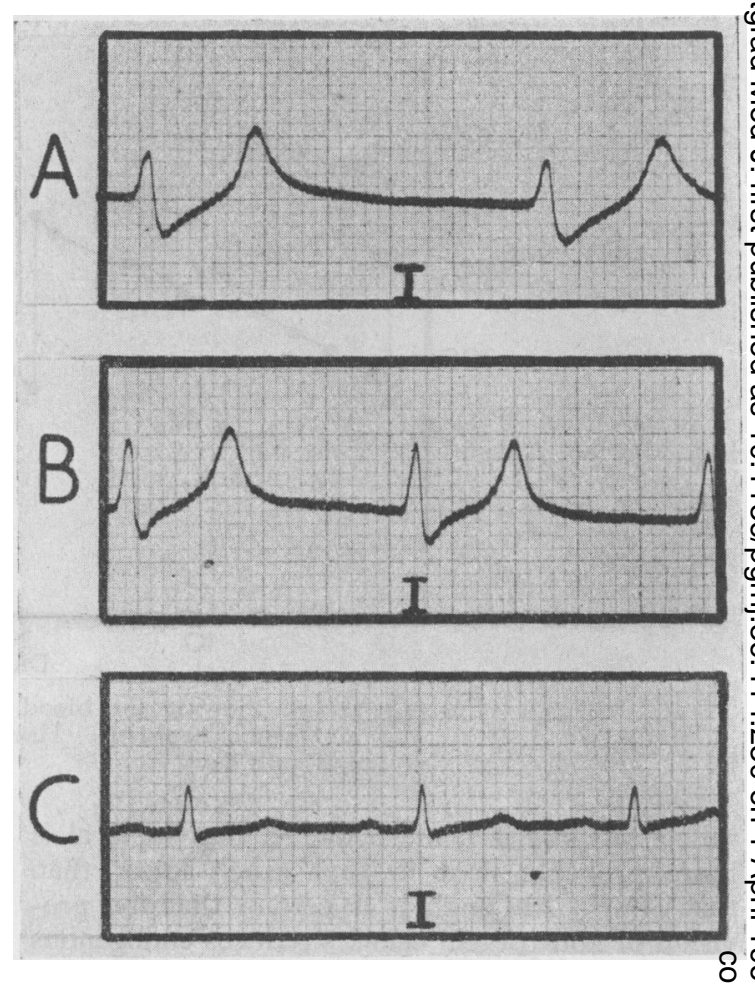

FIG. 2.-Electrocardiographic record, lead $x$, showing the effects of potassium intoxication in a patien. with anuria due to pyelonephritis.

A. On admission. Serum K 8.5 mEq/1.

B. Fifteen minutes after giving intravenous glucose and insulin.

C. After six hours' haemodialysis. Serum K 3.0 $\mathrm{mEq} / \mathrm{l}$.

pH. and can be used as a rough guide to the blood acidity. ${ }^{26}$ On this basis a serum bicarbonate level of $12 \mathrm{mEq} / \mathrm{l}$. is sometimes quoted as an indication for haemodialysis. ${ }^{14}$

Dialysis largely corrects the acidosis as shown by an improvement from 16 to $22 \mathrm{mEq} / \mathrm{l}$. in our patients, accompanied by a relief of the clinical features of acidosis. In no patient with acute $\frac{\mathrm{O}}{5}$ renal failure did the bicarbonate subsequently fall below $12 \mathrm{mEq} / \mathrm{l}$., though a steady fall until fairly late in the diuretic phase was common.

Sodium retention-as evidenced by increasing of oedema with a constant or rising serum sodium- $N$ has been demonstrable in some patients on solid $N_{\omega}^{N}$ diet but has never been sufficient to present a problem in management. This would be anti- o cipated since the retention of the whole of the $\mathbb{D}$ sodium administered over two weeks to an anuric $\stackrel{\infty}{?}$ patient on this diet would only provide 2 litres of $\frac{T}{D}$ extracellular fluid-an amount that can be removed comfc tably at a single dialysis - and most 


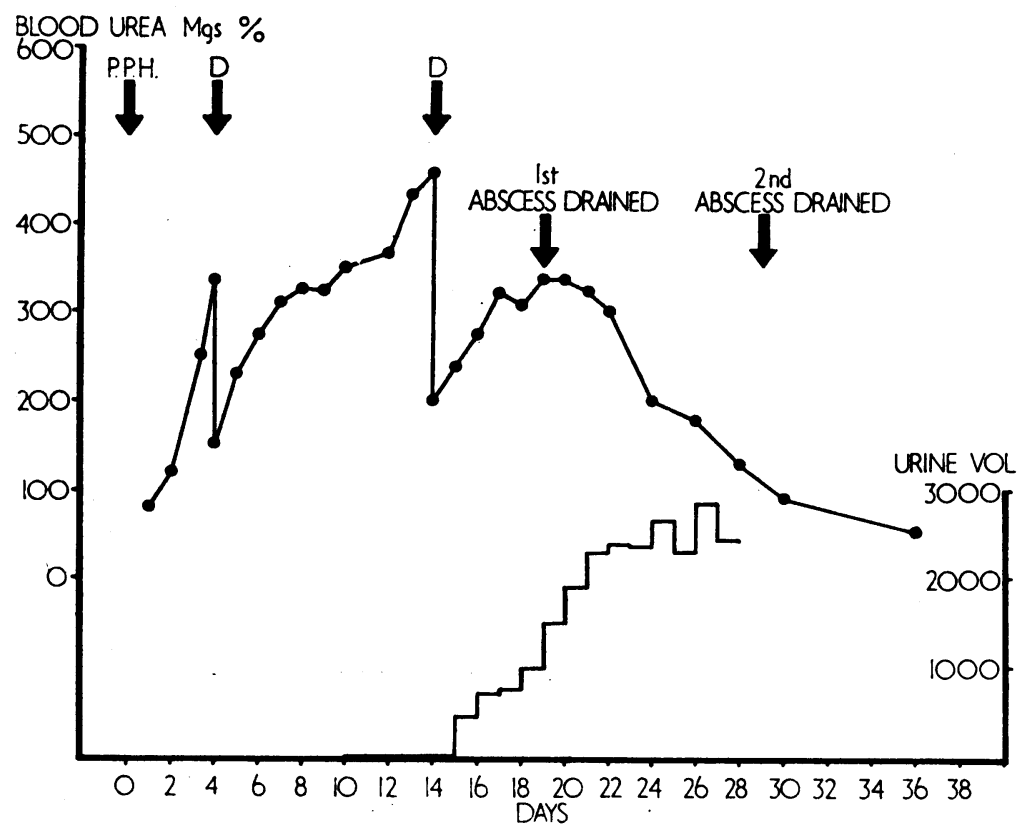

Fig. 3.-Graph showing the blood urea in a patient with acute renal failure following a severe post-partum haemorrhage due to afibrinogenaemia. Haemodialysis was carried out on the $4^{\text {th }}$ and $14^{\text {th }}$ days. Infection occurred on the $17^{\text {th }}$ day.

patients, completely anuric, will require dialysis within that time.

\section{Prevention of Complications}

Infection, haemorrhage, haemolysis and trauma increase the rate of protein breakdown in the body and in severe cases the rate of rise of blood urea may be as high as $150 \mathrm{mg} . / 100 \mathrm{ml}$. in 24 hours, necessitating dialysis as frequently as every 36 hours. One of the main preoccupations of an artificial kidney unit is preventing these complications.

\section{Urinary Infection}

The damaged kidney is highly susceptible to infection. Thirty-two of our 64 patients were catheterized before admission to our unit. In half of these there was either a compelling reason for catheterization such as a fracture of the pelvis, or an established urinary infection. The remaining 16 had been catheterised to confirm the diagnosis of anuria, to obtain specimens for bacteriology or to help in fluid balance. Of these, nine developed urinary infections following the catheterisation, eight with resistant 'hospital' organisms, and five of these have persistent urinary infections after numerous courses of antibiotics and ' urinary antiseptics.' Small errors in calculating fluid balance are less harmful than in- tractable infections, and the practice of catheterizing patients to confirm anuria is to be condemned.

\section{Other Infections}

Next to the urinary tract the commonest sites for infection are the lungs and surgical wounds. The concentration of seriously ill patients with multiple injuries and infections in an artificial kidney unit makes the prevention of cross infection very difficult. Nineteen of our 64 were infectedoften with resistant organisms - on arrival. Thirtyfour patients were barrier nursed. Eight who already had some infection developed further infection in new sites and four developed infection who had been free of it on admission. Sepsis was the main cause of death in ten patients ( $v$. inf.) and remains the greatest unsolved problem. To discourage the emergence of resistant strains, no prophylactic antibiotics are given, and we have reverted to early physiotherapy and ambulation, believing that the risk of lung infection is more serious than the increased protein breakdown associated with exercise. The effect of sepsis in delaying the recovery during the diuretic phase is seen in Fig. 3, and the dramatic reduction in the rate of rise of blood urea when the infection is brought under control is shown in Fig. 4.

One of the difficulties of controlling infection in patients who require dialysis is that each trip to 


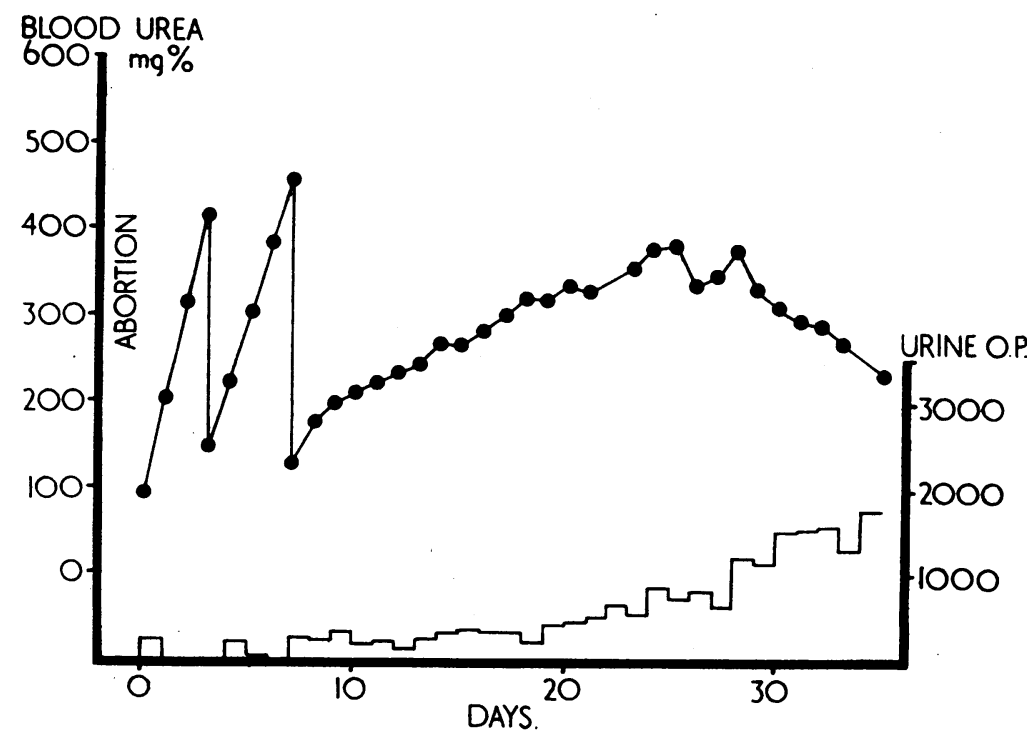

FIG. 4.-Graph showing the blood urea in a patient with renal failure following a septic abortion. Haemodialysis was carried out on the 4 th and 8 th days.

the 'kidney room' involves a break in the barrier nursing routine. The establishment of an extracorporeal circulation for six hours gives rise to the risk of bacteraemia. In all artificial kidneys in current use the dialysing fluid is non-sterile and is a good culture medium for bacteria: bacterial counts in the mixing bath can rise to many thousands per millilitre by the end of a dialysis. The dialysing membrane is impermeable to bacteria and large protein molecules, and we have not so far encountered a positive blood culture during dialysis, nor have pyrogens been found in a dialysate of contaminated 'bath water.' None the less we have been concerned by the frequency of pyrogenic reactions-sometimes with rigorsabout one hour after the start of dialysis; they have occurred in 23 of 80 dialyses. A vigorous search for the cause of these reactions has so far proved negative. They appear to be unpleasant rather than dangerous, but the pyrexia may result in an undesirable increase in protein breakdown.

\section{Haemorrhage}

Minor haemorrhage from surgical wounds was common in our patients and eight suffered major spontaneous haemorrhage-melaena in five, epistaxis in two and fatal pulmonary haemorrhage in one. Severe thrombocytopaenia was contributory to dangerous bleeding in two patients but the platelet count was normal at the time of bleeding in several others. Various clotting defects have been reported in these circumstances. ${ }^{3}$ Haemorrhage was commoner when the blood urea was high and fear of spontaneous haemorrhage is one of the main reasons for advising dialysis when the blood urea reaches $400 \mathrm{mg} / / 100 \mathrm{ml}$. even in asymptomatic patients.

\section{Haemolysis}

The Alwall kidney is technically easy to operate and there have been no 'deaths on the kjdney during 85 dialyses. None the less the procedure iso not without risk, and the main danger is haemolysis of transfused blood. Since the three pints of blood required to prime the machine are intimatelyô mixed and infused into the patient at over $100 \mathrm{ml}$. per minute, great care is needed in cross-matching. Patients who require several dialyses are thereby submitted to repeated rapid transfusions. For these reasons all our patients are genotyped by theRegional Blood Transfusion Service and per- 3 mutation cross-matching is carried out on the blood used to fill the machine. In two patients out of 40 who have been treated by dialysis new antibodies have appeared and jaundice has deepened. In one patient, who had been trans- $-\frac{D}{O}$ fused previously, the antibodies appeared after the first dialysis; in the other, they were first detected $N$ after the fifth dialysis. The pump on the Alwalliv kidney has no valves and measurement of plasma N haemoglobin has shown no detectable haemolysis ${ }^{\omega}$ during the passage of blood through the machine.

\section{Trauma}

Clean surgical trauma has proved the least important cause of increased catabolism, and is fairly well tolerated provided the patient has first under- $\mathbb{\mathbb { D }}$ gone haemodialysis. On this basis we have $\frac{}{\Phi}$ 


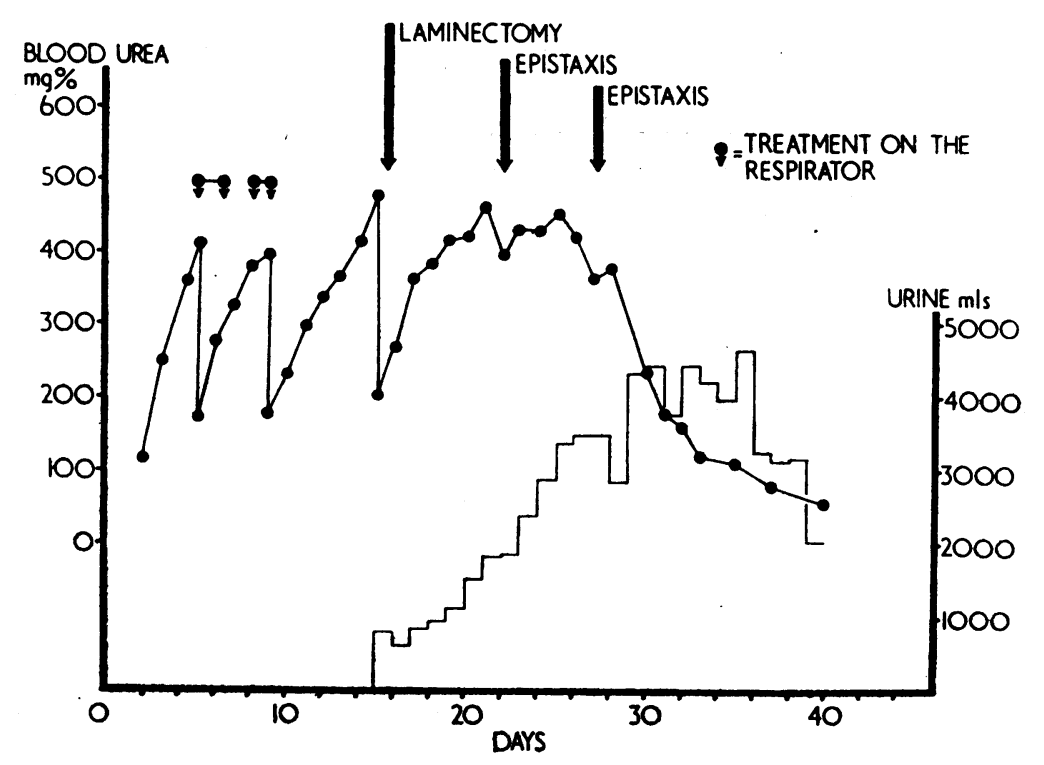

Fig. 5.-Graph showing the blood urea in a case of traumatic anuria. Haemodialysis was carried out on the 4 th, 8 th and $14^{\text {th }}$ days.

carried out dialysis followed by retrograde pyelography and open renal biopsy, liver biopsy or laparotomy on nine occasions to establish a diagnosis in patients admitted with severe uraemia but no history of previous renal disease. Haemorrhage requiring transfusion occurred on two occasions, but there was little evidence of more rapid development of azotaemia.

There is some evidence that haemodialysis itself results in a temporary increase in catabolism. An increased rate of rise of blood urea in the first 24 hours after dialysis has been usual in our patients and in other series, ${ }^{14}$ and in some patients at least an increased production of urea occurs in the latter part of a dialysis which limits the level to which the blood urea can be reduced. This is probably not the only limiting factor.

\section{Analysis of Results}

Of the 64 patients referred, 18 were found to be suffering from irreversible chronic renal disease or malignant disease, two from easily corrected extrarenal uraemia, and in nine uraemia was a complication of severe disease or trauma which caused death within 12 hours of admission. The remaining 35 patients had acute renal failure or an acute exacerbation of compensated chronic renal disease. Twenty-two recovered and went home, eight died in the anuric phase, four in the early diuretic phase and one in the late diuretic phase. Nine of these 13 deaths were attributed to sepsis, and one each to liver failure, haemorrhage, pulmonary embolism and the original injury. Three of the recoveries had 'theoretical maximum ureas '14 of $1,200,1,630$ and $2,700 \mathrm{mg} \cdot / 100 \mathrm{ml}$. respectively.

\section{Summary}

The artificial kidney saves some patients with acute renal failure who would otherwise die of azotaemia or electrolyte imbalance, and probably reduces the severity of some complications, particularly haemorrhage. It can also be used, with caution, to make the conservative management more humane and tolerable to the patient.

\section{Acknowledgments}

The authors wish to thank Professor Smart and Mr. J. Swinney for advice and encouragement. The success of an artificial kidney unit depends on close co-operation with numerous departments, and we are particularly grateful to Professor Green, Dr. A. L. Latner, Professor Duguid, Dr. Sheila Murray, Dr. S. W. Davidson, Sister Freeman and their colleagues for unstinted support.

\section{REFERENCES}

I. ALWALL, N. (1947), Acta. med. scand., 128, 317.

2. ALWALL, N., ERLANDSON, P., NYMAN, N., and TORNBERG, A. (1955), Ibid., 152, 353.

3. BLUEMLE, L. W.. Jr., WEBSTER, G. D., Jr., and ELKINGTON, J. R. (1959), Arch. intern. Med., 104, 180 . 4. BORST, J. G. G. (1948), Lancet, i, 824.

5. BULL, G. M. (I952), Proc. roy. Soc. Med., 45, 848.

6. BULL, G. M. (1955), Lancet, i, 731, 777.

7. BULL, G. M. (1958), Practitioner, 181, 262.

8. BULL, G. M., JOEKES, A. M., and LOWE, K. G. (1949), Lancet, ii, 229 .

Continued on page 260. 
ment which for some surgeons nowadays includes microscopic investigation at the first consultation. Improved optical equipment has made the task very much easier.

Coincident with the development of new ideas of management, observations of another kind were made, more by accident than design. Men began to appreciate that several differing physiologies might be consistent with useful, as opposed to normal hearing. For example, it was noted that a one-ossicle system plus a good membranous cover over the round window might provide nearnormal hearing. Such a modified physiological system was later called by Zollner ' columellahearing.' It was also observed that a mere hypotympanic baffle over the round window, aerated from the Eustachian tube, was consistent with satisfactory hearing, if the oval window were exposed and mobile. This, after all, was not surprising since it resembled the physiology of Lempert's fenestration operation for otosclerotic fixation of the oval window-one mobile window outside the tympanum, and one mobile window inside. These observations were made in cases of old damage wherein spontaneous healing had occurred after varying degrees of destruction. Attempts to reproduce similar conditions surgically gave rise to what we now call tympanoplastic surgery, the principles of which were succinctly codified by Wullstein in the period 1953-1955.

The advent of the new reconstructive concepts gave rise to a wave of untempered enthusiasm since many people thought that the solution of the chronic ear problem lay in doing something rather vague and then adding some kind of skin-graft. However, established principles had not changed and it presently became clear that these techniques were to be regarded as valuable refinements, that inherently they did nothing to eliminate the problem of chronic ear disease.
Tympanoplastic methods are largely applicable to conditions in which reliable healing is to be expected because basic principles have been $\frac{3}{\Phi}$ obeyed, and they produce the best functional 0 results in material which is inactive, or only active $e^{\complement}$ in a limited way beforehand.

I would mention the problem of healing in theo mastoid segment, a difficulty still with us and one음 certainly not eliminated by the large sheets of whole-skin or part-skin originally employed in $₫$ tympanoplastic surgery. The problem has received considerable attention and several attemptss have been made to solve it-for example the limita-. tion of the size of the operative cavity, the use of $\vec{\sim}$ living pedicle skin-flaps, the employment of pedicle-flaps of temporalis muscle, and so on I would repeat that, broadly speaking, recon- 3 . structive surgery is in principle easy where disease

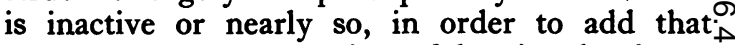
preservation or restoration of hearing is always $\vec{A}$ difficult and sometimes impossible in the presenceiv of advanced pathology.

We are not yet within sight of complete control 군 of chronic middle-ear disease, but we have for aconsiderable time been prepared to confess that the problem persists. The admission arises because men have been willing to acknowledge the bad, $\vec{\oplus}$ sometimes thoroughly bad results of methods? traditionally regarded as sound in principle and in practice. Too often there was no real princip? and too often has it been assumed that orthodox treatment must provide a good result.

\section{REFERENCES}

I. FRASER, J. S. (1927), 'Diseases of the Nose, Throat and Ear, ' ed. by A. Logan Turner, and edition, p. 321 .

2. GRAY, ALBERT (1910), 'The Ear and its Diseases,' p. 182, Bailliere, Tindall and Cox, London.

3. VON TROLTSCH (1874), 'The Surgical Diseases of the Ear, 3 p. 62 (translated by James Finton), The New Sydenhari Society, London.

References continu?d from page 235-The Management of Acute Renal Failure.

9. GAMBLE, J. L. (1947), Harvey Lectures, 42, 247.

ı. GIBSON, L. I. J. M. (1960), Lancet, i, 364 .

Ir. GROLLMAN, E. F., and GROLLMAN, A. (1959), f. clin. Invest., 38, 749 .

12. KOLFF, W. J. (1946), 'The Artificial Kidney,' Kok, Kampen, Holland.

13. Lancet, (1960), i, 371 (Editorial).

14. LOUGHRIDGE, L. W., MILNE, M. D., SHACKMAN, R., and WOOTTON, I. D. P. (1960), Lancet, i, 35 I.

15. LOWE, K. G. (1959), in Ross, E. J. (Ed.), 'Clinical Effects of Electrolyte Disturbances,' Pitman, London, 82.

16. MCCRACKEN, B. H., and PARSONS, F. M. (1958), Quart. F. Med., 27, 566 . ii, 885 .

18. McNAIR, T. J., and DUDLEY, H. A. F. (1959), Ibid., il, 365. N 19. MERONEY, W. H., and HERNDON, R. F. (1954), f. Amer. med. Ass., 155, 877.

20. PARSONS, F. M. (1959), Lancet, i, 148.

21. PIERCE, J. M. (1958), F. Urol., 80, 170.

22. SALISBURY, P. F. (1958), Arch. intern. Med., 101, 690

23. SCRIBNER, B. H. (1959), Northw. Med., Seattle, 58, 555.?

24. SHAW, G. (1959), Lancet, i, 15.

25. TAYLOR, W. H. (1957), Ibid., ii, 703.

26. TUCKER, D. A., WELLER, J. M., and MERRILL, J. P.T (1958), Amer. F. med. Sci., 236, 567. 